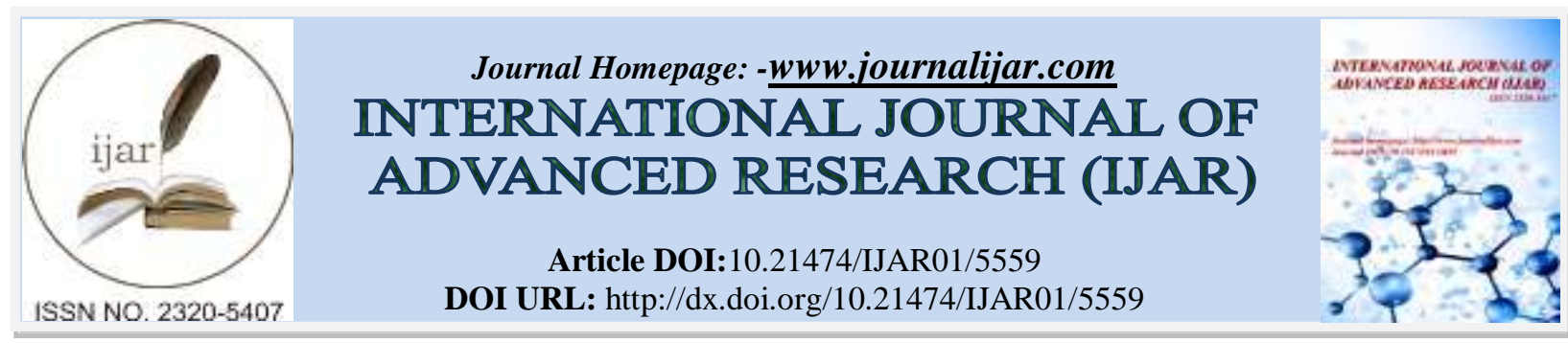

RESEARCH ARTICLE

\title{
UNUSUAL CAUSE OF PELVIC PAIN IN WOMEN: URACHAL CYST.
}

\section{Ouadie El Menaoui ${ }^{1}$, Badr Chaoui ${ }^{1}$, Rachida Latib $^{2}$, Ilham Chami ${ }^{2}$ and M. N Boujida ${ }^{2}$.}

1. Military training hospital Mohamed-V, Rabat, Morocco.

2. Hospital MoulayAbdellah of oncology, Rabat, Morocco.

\section{Manuscript Info}

Manuscript History

Received: 07 August 2017

Final Accepted: 09 September 2017

Published: October 2017

Key words:-

Urachal cyst- Infection- MRI.

\begin{abstract}
The urachus is an embryologic remnant which degenerates after the birth. Defective obliteration of the urachus usually detected in childhood leads to urachal abnormalities and it may persist as cyst, fistula, sinus or diverticulum. They are very rarely seen in adults. Infection is the most common complication and the major risk is malignant degeneration. We report a case of urachal abscess which is originated from urachal cyst in an adult woman.
\end{abstract}

Copy Right, IJAR, 2017,. All rights reserved.

\section{Introduction:-}

The urachus is an embryologic remnant located in the midline and extends from the apex of the bladder to the umbilicus. Its role is not defined. The urachus degenerates after the birth and it is named as median umbilical ligament. Defective obliteration of the urachus leads to abnormalities and it may persist as cyst, fistula, sinus or vesico-urachal diverticulum. Urachal abscess is an uncommon complication of the urachal abnormalities and it occurs especially rarely in adults. We report a case of urachal abscess in an adult woman.

\section{Case report:-}

A 46 year old woman presented to the emergency with hypogastric pain, fever, signs of bladder irritation which lasted for a few days. The physical examination revealed signs of pelvi-peritonitis: hypogastric contracture, periumbilical tenderness, erythema and discharge from the umbilicus. The laboratory tests were all within the normal limits. The ultrasound shows impure pubic cystic mass suggesting an abscess within the abdominal anterior wall. An MRI performed with bladder catheter confirmed the presence of an infected cyst, as a cystic signal formation (high signal fluid in T2-weighted) a head the bladder in the midline of the abdominal wall with no communication with the bladder (figure 1; figure 2), heterogeneous enhancement and thickening of mesenteric fat (figure 3; figure 4). The patient was given antibiotics and prepared for surgery. Pathological examination revealed an infected urachal cyst.

\section{Discussion:-}

The urachus is an embryonic connection between the bladder dome and the umbilicus. The urachus is obliterated by the fifth to seventh month of gestation and it forms the median umbilical ligament who lies between the transversalis fascia and parietal peritoneum in the space of retzius [1,2], its length varies from 3 to $10 \mathrm{~cm}$ and its diameter from 8 to $10 \mathrm{~mm}$. Urachal anomalies are more commonly found in males and are rarely observed in adulthood. The congenital anomalies of the urachus are: 1-the cyst of the urachus, it's a cyst without communication with the bladder or the umbilicus due to cranial and caudal obliteration. 2-fistula of the urachus, communicating the bladder to the umbilicus clinically we have flow of urine through the umbilicus. 3-Urachal sinus (umbilical cyst or external 
sinus), which drains proximally into the umbilicus. 4-diverticulum of the urachus, cystopened in the bladder, it results from the cranial obliteration of the urachus while the caudal part is not [3]. Infection is the most common complication and the major risk is malignant degeneration [1]. The commonly cultured micro-organisms from the cystic fluid include Escherichia coli (such our case), Enterococcus faecium, Klebsiella pneumonia, Proteus, Streptococcus viridans and Fusobacterium [1,4]. Typical clinical manifestations of patent urachal pathologies-as seen in our case- are umbilical discharge, tenderness, or a mass within the umbilicus. Abdominal pain can be the only symptom of disease, and can mimic an acute abdomen due to appendicitis or Meckel's diverticulum [2]. The differential diagnosis of an umbilical mass should include hematoma, abscess, umbilical hernia, urachal carcinoma and tumors of the abdominal wall. Ultrasound may be useful but not sufficient, CT is the most indicated, but the best accuracy is given by the MRI [3] -Such in our case- Literature does not describe the contribution of magnetic resonance imaging such as diffusion [5,6], finding a similar appearance to the globally heterogeneous scanner with a central fluid, or necrotic suppurated component and a solid portion with significant enhancement after contrast. This non-specific aspect does not make it possible to distinguish a tumour or infectious origin. Punctiform calcifications or large calcified plaques are strongly suggestive of adenocarcinoma of the urachus. The recommended treatment is administration of antibiotics initially till the resolution of inflammation, followed by surgical removal (complete excision, with or without the cuff of the bladder, is sufficient). It is not necessary to remove the umbilicus [4].

\section{Conclusion:-}

Urachal pathology in adulthood is rare, it remains asymptomatic for a long time and can be discovered on occasion of a complication. Infection is the most frequent complication; the suppurated cyst may fistulate to the umbilicus or bladder, or ruptures in the peritoneal cavity leading to peritonitis.

The diagnosis of is mainly clinic and the diagnosis is usually confirmed by ultrasonography, computed tomography (CT), and also magnetic resonance imaging (MRI).

\section{Competing interests:-}

The authors declare that they have no competing interests.

\section{Figures:-}

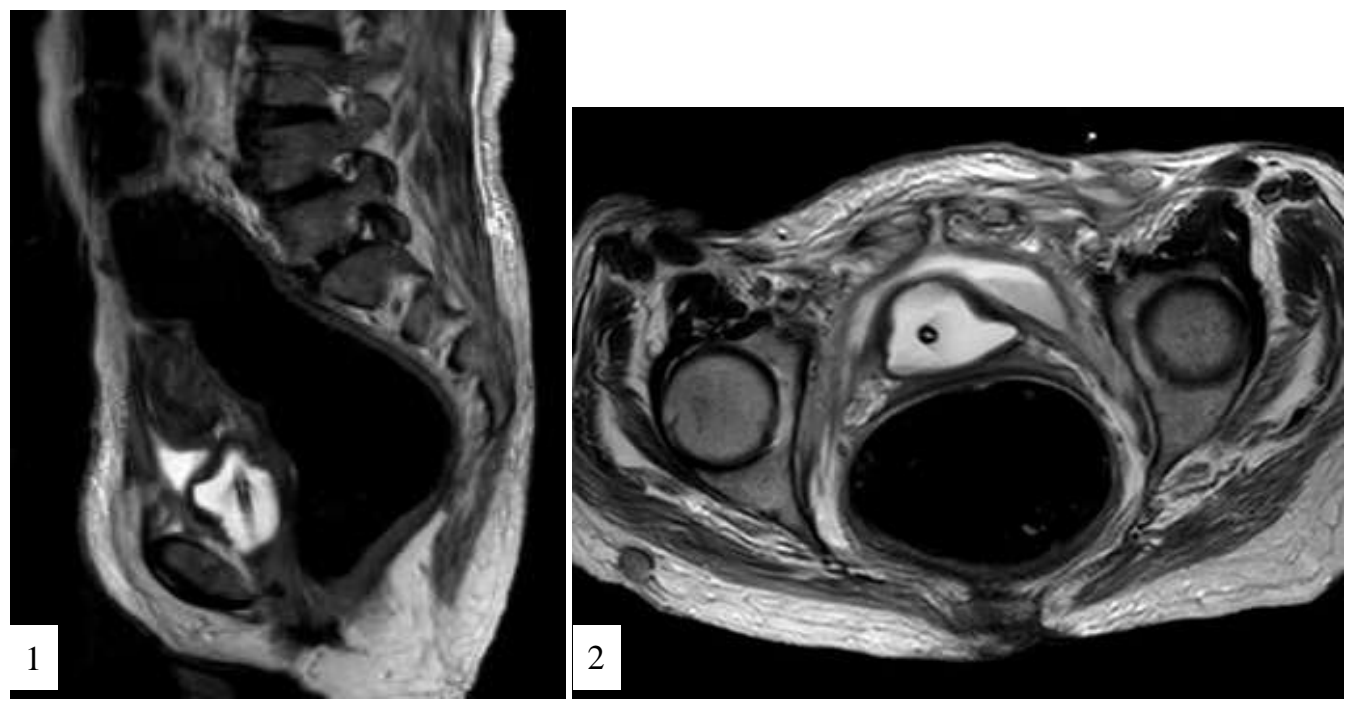

Figure 1:- T2-weighted sagittale / Figure 2: T2-weighted axial

Medial pelvic formation, under parietal, located between the bladder dome and the umbilicus, high signal fluid in T2-weighted. 


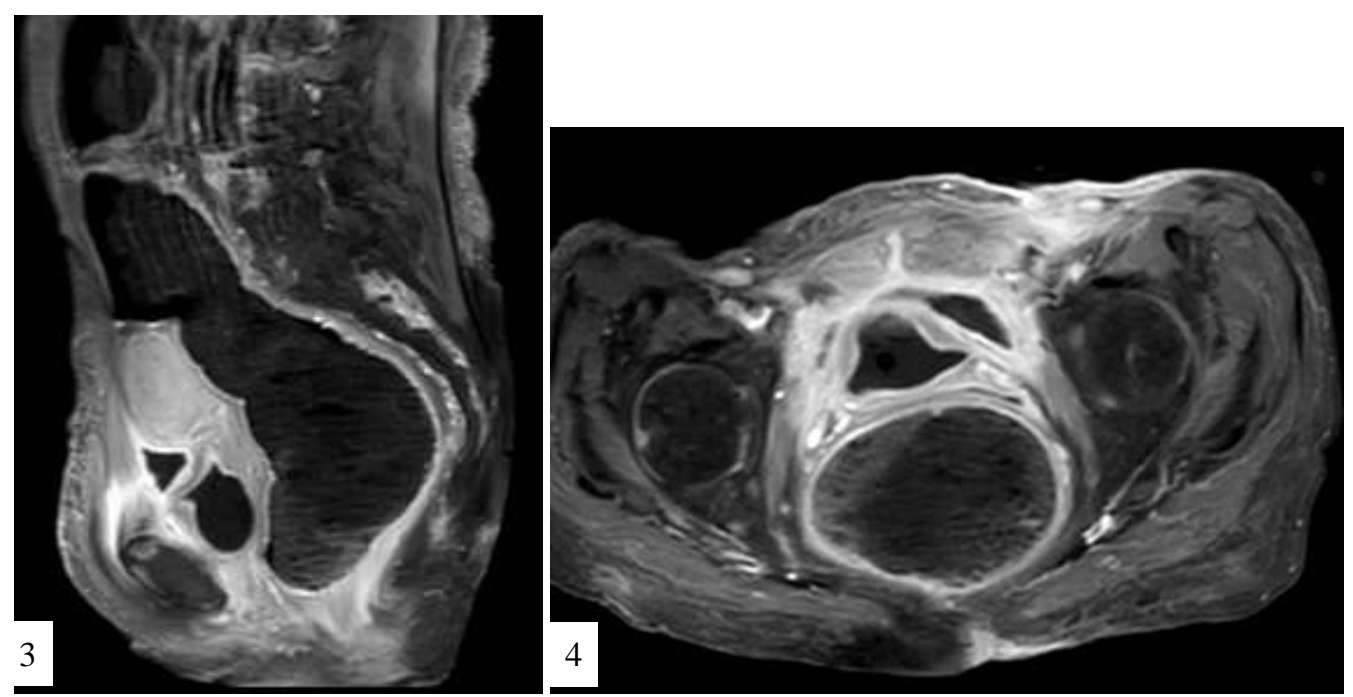

Figure 3:- Gadolinum enhanced sagittale T1 / Figure 4:Gadolinum enhanced axial T1

Note the intense enhancement of the wall of this formation (which is hypo signal T1) and the soft tissue of the abdominal wall as well as the intra-peritoneal fat on contact.

\section{References:-}

1. Ashley RA, Inman BA, Routh JC, Rohlinger AL, Husmann DA, Kramer SA. Urachal anomalies: a longitudinal study of urachal remnants in children and adults . J Urol. 2007 Oct;178(4 Pt 2): 16158. Epub 2007 Aug 16

2. Qureshi K, Maskell D, McMillan C, Wijewardena C: An infected urachal cyst presenting as an acute abdomen A case report. Int J Surg Case Rep. 2013;4(7):633-5. doi:10.1016/j.ijscr.2013.02.026. Epub 2013 Apr 19

3. Arifa N, Hasni I, Khadraoui H, Mhiri M, Jemni H, Derbel F, Ben Sorba N, TliliGraiess K : Atlas d'imagerie de l'ouraque du normal au pathologique. JFR: 2004

4. Yoo KH, Lee SJ, Chang SG: Treatment of infected urachal cysts. Yonsei Med J. 2006 Jun 30;47(3):423-7.

5. Renard O, Robert G, Guillot P, Pasticier G, Roche JB, Bernhard JC, Azizi A, Ferrière JM, Wallerand H: Benign urachus abnormalities: embryology, diagnosis and treatments. Prog Urol. 2008 Nov;18(10):634-41. doi: 10.1016/j.purol.2008.04.026. Epub 2008 Aug 15

6. Rafal R.B., Markisz J.A: Urachal carcinoma: The role of magnetic resonance imaging. Urol Radiol. 1991;12(4):184-7. 